\title{
DOUTRINA
}

\section{O DESVIO DE PODER NO CONTROLE DOS ATOS ADMINISTRATIVOS, LEGISLATIVOS E JURISDICIONAIS}

\author{
CAIO TÁCITO
}

I - Desvio de poder administrativo. II - Desvio de poder Legislativo. III

- Desvio de poder jurisdicional.

\section{I - Desvio de Poder Administrativo}

A Administração Pública exerce a função que lhe é própria mediante atos administrativos com os quais a autoridade competente, fundada em norma de direito, cuida de alcançar os resultados adequados ao interesse coletivo.

Não trata a autoridade de interesse próprio ou individual. A ação que exerce tem como endereço uma finalidade pública, que não pode descumprir.

Enquanto no ato jurídico privado as razões que inspiram o autor, bem como o objetivo a ser alcançado, são, via de regra, indiferente à validade do ato, o mesmo não ocorre com o ato jurídico público e, especialmente, com o ato administrativo.

Qualquer ato administrativo está vinculado a um fim público, ainda que a norma de competência a ela não se refira.

A manifestação de vontade do agente público terá, necessariamente, que se dirigir à observância da finalidade específica relacionada com a natureza da atividade exercida.

Se a autoridade se desvia da finalidade legal específica, o ato administrativo se torna viciado em elemento essencial à sua legalidade.

Caracteriza-se, na hipótese, o vício que se conceituou como desvio de finalidade ou desvio de poder.

A terminologia é expressiva e procura indicar, graficamente, o movimento ilícito da vontade que, descumprindo a ordem da lei, dirige-se a um alvo diverso daquele que lhe é determinado.

A noção de détournement de pouvoir como vício de legalidade do ato administrativo foi construída na jurisprudência do Conselho de Estado da França a partir do famoso caso Lesbats, decidido em 25.2.1864 e confirmado em 7.6.1865, no qual se 
firmou o entendimento de que o recurso por excesso de poder compreendia o caso em que a autoridade praticasse determinado ato no uso de seus poderes legais, porém visando a fim diverso daquele previsto, explícita ou implicitamente, na regra de competência. Cuidava-se de autorização da Municipalidade para o estacionamento de veículos em praça fronteira à estação de estrada de ferro para atender ao transporte de passageiros. Evidenciou-se, à luz da prova, que a negativa de autorização a determinado transportador (ato, em princípio discricionário) obedecia, em realidade, ao propósito de garantir a exclusividade do serviço a outra empresa (sobre o teor do aresto Lesbats, ver: Henri Welter, "Le Controle Jurisdicional de la Moralité Administrative", 1929, pp. 161/164).

A anulação de casos de monopólios velados, no tocante a estacionamento de veículos, renovou-se em outros arestos do Conselho de Estado (arrêt Bouchardon, 2.8.1870, e arrêt Ville de Cannes, c. Rabé, 8.6.1917; este último objeto de comentário de Maurice Hauriou in "La Jurisprudence Administrative de 1892 a 1929", Tomo II, p., 343).

O desvio de poder é, por definição, um limite à ação discricionária, um freito ao transbordamento da competência legal além de suas fronteiras, de modo a impedir que a prática do ato administrativo, calcada no poder de agir do agente, possa dirigir-se à consecução de um fim de interesse privado, ou mesmo de outro fim público estranho à previsão legal.

Com esse sentido, o conceito se transferiu ao direito italiano com a noção de sviamente di potere, adotado pelo conselho de Estado na Itália, com fórmulas variadas, que apresentam como base o uso de uma faculdade discricionária para um fim diverso daquele para o qual foi concedida pela norma de direito (Renato Alessi, "sistema Instituzionale del diritto Amministrativo Italiano", Giuffré, 1953, pp. 306 e ss.).

Com semelhante abrangência, o vício de legalidade em causa encontra paradigma no direito de outros países, inclusive no peculiar sistema anglo-saxão, em que o abuse of discretion se fundamenta na regra de subordinação da competência ao fim legal (subordination to scope).

A par de levantamento amplo da recepção do conceito no direito comparado, tivemos oportunidade de documentar, há 40 anos, a acolhida do desvio de poder na doutrina e na jurisprudência brasileiras em tese de habilitação à livre docência na Faculdade de Direito da Universidade do Rio de Janeiro, em 1951 (Desvio do Poder em Matéria Administrativa, in Temas de Direito Público - volume I - p. 71/s.).

$\mathrm{Na}$ oportunidade, destacamos que o acórdão pioneiro de 28.7.1948, do Tribunal de Justiça do Rio Grande do Norte, relatado pelo então Des. Seabra Fagundes, acolhendo a noção do desvio de finalidade (RDA, vol. 14, p. 52), guardava analogia com o precedente francês do referido caso Lesbats.

Tratava-se de mandado de segurança versando sobre o exercício do poder de polícia de trânsito, por parte de autoridade estadual competente, fixando horário para o tráfego intermunicipal de determinada empresa de ônibus que importava em prejudicá-la em benefício de empresa concorrente. Acolhendo o voto do Relator, o Tribunal decidiu pela nulidade do ato, que não atendia ao fim legal de bom funcio- 
namento do serviço de transporte, mas objetivava outro fim estranho de favorecimento de terceiro.

A teoria do desvio de poder adquiriu renovada consagração na jurisprudência e na doutrina nacionais e alcançou definitiva afirmação na lei sobre ação popular (Lei n. 4.117, de 29.6.1965), cujo art. $2^{\circ}$ inscreve o desvio de finalidade entre os casos de nulidade, definindo que sua ocorrência "se verifica quando o agente pratica $o$ ato visando a fim diverso daquele previsto, explícita ou implicitamente na regra de competência" (alínea $e$ do citado art. $2^{\circ}$ ).

Pacificamente se firmou, assim, entre nós, a acolhida do desvio de poder como forma típica de nulidade de atos administrativos.

Depõe Hely Meirelles no sentido de que "não se compreende ato administrativo sem fim público (...) A finalidade do ato administrativo é aquela que a lei indica explícita ou implicitamente. Não cabe ao administrador escolher outra ou substituir a indicada norma administrativa, ainda que ambas colimem fins públicos. Nesse particular, nada resta para escolha do administrador, que fica vinculado integralmente à vontade legislativa" (Hely Lopes Meirelles, "Direito Administrativo Brasileiro", $14^{a}$ ed., 1989, pp. 128 e 129).

No mesmo diapasão opina Celso Antônio Bandeira de Mello: “À lei não é indiferente que se use para perseguir dado escopo, uma ou outra competência. Cada qual tem seu destino certo. Cada "poder" - que uma competência administrativa exprime - nada mais é que a face reversa do dever específico de implementar certa finalidade legal. Mesmo quando se trata de buscar um objetivo juridicamente qualificado como prestável, cumpre fazê-lo pelo meio definido pela lei como a via idônea para chegar a tal fim" (RDA 172/7).

A lição clássica de Roger Bonnard já adotava esse entendimento, quando assim fixava a vinculação do ato administrativo ao fim legal e obrigatório:

"En matière de but, il n'y a jamais pour l'administration un puvoir discrétionnaire. Car il ne lui st jamais laissé pouvoir de libre appréciation quant au but à poursuivre. Le but este toujours imposé par les lois et règlemente soit explicitemente, soit implicitement" (Précis de droit administratif, 1935, p. 228).

A doutrina italiana assentou o princípio idêntico de que a causa emanada da lei, integra e tipifica os atos administrativos, conforme elucida Cino Citta:

\begin{abstract}
"Poichè l'atto amministrativo è per sua natura unilaterale, genericamente esso si appogia sull'utile pubblico, ed è doutrina corrente che ciascuna caegoria di atti amministrativi abbia poi la sua causa quella particolare specie di utilie pubblico che il legisllatore abbia per essa determinada" (Direito administrativo, $3^{\mathrm{a}}$ ed., 1948, v. 1, p. 376).
\end{abstract}

Não é outro, através das variações terminológicas, o sentido com que, no direito anglo-saxão, o poder discricionário tem como um de seus balizamentos, o objeto (purpose) determinado pela lei. 
Eis o depoimento autorizado de S.A. de Smith, quanto ao direito inglês.

"Discretionary powers must be exercised for the purpose for which they were granted (...). In general, a discretion must be exercised only by the authority to which it is committed (...). It must act in good faith, must have regard to all relevant considerations must not most seek to to promote purpose alien to the letter or the spirit of the legislation that gives It power to act, and must not acto arbitrarily or capriciously" (Judicial Review of Administrative Action, $1^{a}$ ed., 1959, pp. 61 e 72).

No mesmo sentio, Hood Phillip (The Constitional Law of Great Britain and the Commonwalth, 1952, p. 406).

Reaparece o mesmo conceito na literatura jurídica de língua espanhola, como - para referir um exemplo entre muitos - poder-se-á encontrar no trecho seguinte de Sayaguès laso:

"(...) Los órganos de administración se encuentram en una situación de deber, para cumplir la cual el derecho les asigna determinados poderes jurídicos. Por lo tanto, al ejercer poderes han de guiar-se por el fin proprio del servicio a su cargo prescindiendo de toda idea extraña que pueda desviarlos de sua linea de conducta natural (...)" (Tratado de derecho administrativo, 1953, v. 1, p. 449).

Seria interminável o rol de citações com que poderíamos abonar a compreensão universalmente aceita de que o respeito à finalidade legal - expressa ou implicitamente contida na norma de direito - é condição essencial de legalidade dos atos administrativos.

\section{II - Desvio de Poder Legislativo}

No exercício de suas atribuições e nas matérias a eles afetas, os órgãos legislativos, em princípio, gozam de discricionariedade peculiar à função política que desempenham.

Temos, contudo, sustentado a necessidade de temperamento da latitude discricionária de ato do Poder Legislativo, ainda que fundado em competência constitucional e formalmente válido.

O princípio geral de direito de que toda e qualquer competência discricionária tem como limite a observância da finalidade que lhe é própria, embora historicamente vinculado à atividade administrativa, também se compadece, a nosso ver, com a legitimidade da ação de legislador.

Tivemos oportunidade de sustentar, perante o SSTF, em duas oportunidades, a nulidade de leis estaduais em que, ao término de governos vencidos na urnas, eram criados cargos públicos em número excessivo, não reclamados pela necessidade pública e comprometendo gravemente as finanças do Estado, tão-somente para o aproveitamento de correligionários ou de seus familiares.

Para o desfazimento dessas leis que caracterizam os chamados testamentos políticos, o STF consagrou a tese da validade de novas leis, anulando leis inconsti- 
tucionais, reconheciam o abuso pelos poderes legislativos estaduais da competência, em princípio discricionário, da criação de cargos públicos.

O primeiro acórdão, proferido no MS n. 7.243, em sessão de 20.01.1969, manteve a anulação de leis do Estado do Ceará com as quais, no apagar das luzes de uma situação política derrotada, em apenas 56 dias, mediante 25 atos legislativos, foram instituídos, sob a forma de criação ou transformação, 3.784 novos cargos públicos, o que equivalia a um terço do total do funcionamento estadual então existente, estimado em 12.000 servidores, elevando o custo mensal do pessoal a 94,24\% das rendas do Estado.

Por essa forma, violava-se norma expressa da Constituição estadual, que fixava o teto de $50 \%$ para a vinculação da receita ao custo do funcionalismo público e se objetivava impedir o funcionamento regular do Poder Executivo, no período do novo mandado que ia inaugurar.

Em comentário a essa decisão, que firmou precedente memorável, destacamos a importância da tese por ela abonada:

"A competência legislativa para criar cargos públicos visa ao interesse coletivo de eficiência e continuidade da administração. Sendo, em sua essência, uma faculdade discricionária, está, no entanto, vinculada à finalidade, que lhe é própria, não podendo ser exercida contra a conveniência geral da coletividade, com o propósito manifesto de favorecer determinado grupo político, ou tornar ingovernável o Estado, cuja administração passa, pelo voto popular, às mãos adversárias".

Tal abandono ostensivo do fim a que se destina a atribuição constitucional configura autêntico desvio de poder (détournement de pouvoir), colocando-se a competência legislativa a serviço de interesses partidários, em detrimento do legítimo interesse público" (RDA, vol. 59, pp. 347 e 348).

A mesma situação se renovou, no Estado do Rio Grande do Norte, perante outro estamento político de um governo vencido no pleito eleitoral sucessório, em que se comprometia desmedidamente o erário, elevando a mais de $80 \%$ a despesa com o funcionalismo público.

Em decisão proferida na Representação n. 512, julgada, por unanimidade, pelo Tribunal Pleno, em sessão de 7.12.1962, o STF reputou legítima a anulação, pela Assembléia Legislativa, de leis inconstitucionais que compunham o testamento político em causa.

Em memorial oferecido como advogado do novo governo estadual ponderávamos que "o desvio de poder legislativo, caracterizado no inventário político, ofende o princípio da independência e harmonia dos poderes, além de violar a Constituição estadual".

Em acórdãos posteriores nos REs ns. 48.655 e 50.219 (RDA, vol. 73, pp. 269 e 281), aplicando a orientação firmada, a Corte Suprema reafirmou a tese na anulação, pelo Poder Legislativo, de seus próprios atos inconstitucionais.

A acolhida do cabimento do desvio de finalidade como vício de inconstitucionalidade for a anteriormente abonada em outro julgado do STF, em voto do Min. 
Orosimbo Nonato, Relator do RE n. 18.331, que, nos termos da respectiva ementa, após recordar o conhecido axioma de que o poder de taxar não se pode extremar como poder de destruir, destaca: "é um poder cujo exercício não deve ir até o abuso, o excesso, o desvio, sendo aplicável, ainda aqui, a doutrina fecunda do détournement de pouvoir" (Revista Forense, vols. 145 e 146).

O excesso do poder de taxar foi igualmente repelido com respeito à lei do Estado do Rio de Janeiro que exigia taxa judiciária em termos excessivos, sem correspondência com o serviço prestado (Representação n. 1.077 - RTJ, vol. 111, p. 55).

Comentando o sentido inovador da jurisprudência do Pretório Excelso, registra Seabra Fagundes, entre as fecundas criações pretorianas, "a extensão da teoria do desvio de poder originária e essencialmente dirigida aos procedimentos dos órgãos executivos, aos atos do poder legiferante, de maior importância num sistema de Constituição rígida, em que se comete ao Congresso a complementação do pensamento constitucional nos mais variados setores da vida social, econômica e financeira" (Revista Forense, vol. 151, p. 549).

Em decisão de 31.08.1967, no Recurso em MS n. 16.912, o tema do desvio de poder como vício especial de ato legislativo foi expressamente invocado.

Apreciando lei de organização judiciária na qual se inserira emenda em benefício de determinado serventuário, advertiu o Min. Prado Kelly: Tratava-se de reforma judiciária e a emenda representou um desvio de poder da própria legislatura".

São do mesmo Ministro as seguintes expressões:

"Tenho por demonstrado que a emenda não obedeceu ao presumido escopo de interesse público, e sim a uma inspiração que nem por ser equânime ou reparadora (como pareceu ao interveniente) deixa de ser particularista ou de favorecimento pessoal".

Nessa decisão plenária, o Min. Victor Nunes Leal, após aderir à posição "de que podemos exercer controle sobre os desvios de poder da própria legislatura", convocado, por interpelação do Min. Aliomar Baleeiro, a declarar "se admitia um desvio de poder do Poder legislativo for a do caso de inconstitucionalidade", não vacilou em afirmar categoricamente "Admito" (acórdão no RMS n. 16.912 - RTJ, vol. 45 , pp. 530-545, especialmente pp. 536 e 537).

Em questão relativa à permissão para explorar linhas de ônibus, o STF apreciou a incidência de desvio de poder legislativo, admitindo, em tese, a aplicação do princípio (RTJ, vol. 47, p. 650 e vol. 48, p. 165).

Em três situações, o STF repeliu, por inconstitucionalidade, a aplicação de sanções administrativas com a finalidade real de constranger o contribuinte à regularidade fiscal.

Decidiu a Corte Suprema que "é inadmissível a interdição de estabelecimento ou a apreensão de mercadorias como meio coercitivo para cobrança de tributo" (Súmulas nos 70 e 323).

E, dilatando o princípio à inconstitucionalidade dos DLs $n^{\mathrm{os}} 5$ e 42, de 1937 que restringiam indiretamente a atividade comercial de empresas em débito, impedindo-as de comprar selos ou despachar mercadoria - implicitamente configurou 
o abuso de poder legislativo (Súmula n. 547 e acórdão no RE n. 63.026 - RDA, vol. 10, p. 209).

O excesso legislativo foi convocado em acórdão do STF no RE n. 62.731, do qual foi relator foi relator o Min. Aliomar Baleeiro. Afirmou-se a inconstitucionalidade de decreto-lei que vedava a purgação de mora em locações. Destacou a ementa da decisão a impertinência do fundamento por se tratar de "assunto miúdo de direito privado" que não se incluía no conceito de segurança nacional, necessário àquela forma de processo legislativo (RDA, vol. 94, p. 169).

O poder de polícia das profissões somente pode ser exercido com observância do princípio da razoabilidade, afirmou o acórdão na Representação n. 930.

E porque o impedimento do exercício profissional da advocacia a juízes aposentados até dois anos após a inatividade ofendia ao princípio da razoabilidade, foi declarada a inconstitucionalidade da lei que estabelecia tal interdição temporária, por violação àquele princípio (Representação n. 1.054 - RTJ, vol. 112, p. 7).

Em parecer no qual analisamos a inconstitucionalidade de deliberação do Banco Central do Brasil determinante da indisponibilidade de contas bancárias do Estadomembro a suas empresas, enfatizávamos que "importa desvio do Poder Legislativo decreto-lei que se utilize do bloqueio de contas bancárias como meio de cobrança regressiva de aval a empréstimos externos" (RDA, vol. 172, p. 239).

Em outro parecer relativo à validade da lei municipal que subordinava a permissão de funcionamento de estabelecimentos comerciais aos sábados e domingos à prévia aprovação pelos órgãos sindicais, entendíamos ocorrer violação da competência legal a ser exercida pelo Município, como emanação do poder de polícia,

Ressaltamos que, obrigando à intervenção dos sindicatos para a obtenção de licença especial de funcionamento, o legislador teve em mira o fortalecimento do sistema sindical, invadindo órbita de competência privativa da União.

Concluímos, assim, que "à toda evidência, a lei municipal, visando a beneficiar o movimento sindical, está maculada pelo vício de abuso do poder normativo, caracterizado como desvio de finalidade" (RDA, vol. 164, p. 460).

O tema do desvio de poder legislativo foi amplamente estudado, no direito italiano, por Livio Paladin, em ensaio sob o título Osservazioni Sulla Discrezionalità e Suli Eccesso di Potere del Legislatore Ordinario (in Rivista Trimestrale di Diritto Pubblico, ano VI, n. 4, out/dez. 1956, pp. 993/1.046).

Pondera o auto que: "I illegitimità di ogni fine, diverso da quello costituzionalmente previsto, consente logicamente di configurare, sul piano legislativo, qual vizio della causa degli atti amministrativi, che è l'eccesso di potere" (a ilegitimidade de todo fim, diverso daquele constitucionalmente previsto, conduz logicamente a configurar-se, no plano legislativo, aquele vício de causa dos atos administrativos, que é o excesso de poder - ob. cit., p. 1.031).

A figura do desvio de poder legislativo foi, pioneiramente, sustentado por Santi Romano que, reconhecendo o poder discricionário do legislador, destaca, porém, o limite que se impõe em face da finalidade da competência legislativa:

"Mas la figura dele potere discrezionale richiede per lappunto che di esse si faccia uso conforme alle finalità da cui il potere medesimo deriva; si ha altrimenti uno sviamento di potere, che constituisse una viclazione di diritto, nel senso più 
proprio della parola. Son concetti questio di commune applicazione reiguardo aile competenza degli organi amministrativi e non si saprebe indicare il perchè non possono riferirsi, nella loro generali à, al Parlamento. In certi campi della sua funzione legislativa, questo non ha poteri sconfinati, ma poteri disricionali il che vuol dire limitate, e non altro, dall'obbigo di farne uso per dali motivi" (mas a figura do poder discricionário reclama precisamente que dele se faça uso conforme à finalidade, da qual o próprio poder deriva: há de outra forma um desvio de poder, que constitui um violação de direito, no sentido próprio da palavra. São conceitos estes de aplicação comum no que se refere à competência dos órgãos administrativos, e não se saberá indicar por que não parecem se referir, em sua generalidade, ao Parlamento. Em certos campos de sua competência legislativa, este não possui poderes sem fronteiras, mas poderes discricionários, importa dizer, limitados pelo menos da obrigação de fazer uso por motivos determinados) (Santi Romano, Osservazioni Preliminari per una Teoria sui Limite della Funzione Legislativa nel Diritto Italiano, publicado no "Arquivo dell' Diritto Pubblico", 1902, e incluído na coletânea "Scriti Minori", vol. 1, "Diritto Constitucionale", 1950, p. 199).

Não é outro o pensamento de Mortati quando adverte que "a lei poderá estar viciada de inconstitucionalidade não somente quando o interesse perseguido contesta com aquele imposto pela Constituição, mas também nos casos em que o próprio teor da lei está em absoluta incongruência com a norma editada e o fim do interesse público a ser perseguido, e o próprio legislador afirma pretende perseguir. Verificase, nessa última hipótese, uma modalidade de vício de legitimidade assinalável ao excesso de poder administrativo" (la legge puó risuliare viziata per inconstituzionalità non solo quando l'interesse pers guit contrasta con quello imposto dalla costituzione, ma anche nei casi in cui dallo siesso tenore della legge risulti un'assoluta incongruenza fra la norma dettata ed il fine di publico interesse che si doveva perseguire e che lo stesso legislatore asume di volere perseguire. Si verificherebbe in quest'ultima ipotesi un'ipotesi di dizio della legittimità assimilabile a quelo dell accesso di potere amministrativo) (Costantino Mortati, verbete Discriconalità, "Novissimo Digesto itlaiano", vol. V. p. 1.109).

Entendemos, em suma, que a validade da norma de lei, ato emanado do Legislativo, igualmente se vincula à observância da finalidade contida na norma constitucional que fundamenta o poder de legislar.

$\mathrm{O}$ abuso de poder legislativo, quando excepcionalmente caracterizado, pelo exame dos motivos, é vício especial de inconstitucionalidade da lei pelo divórcio entre o endereço real da norma atributiva da competência e o uso ilícito que a coloca a serviço de interesse incompatível com a sua legítima destinação.

Gilmar Ferreira Mendes dedicou capítulo especial de sua monografia sobre controle de constitucionalidade à avaliação do excesso de poder legislativo como vício substancial de inconstitucionalidade. Com apoio na doutrina alemã e na lição de CANOTILHO, evidencia a prevalência da vinculação do ato legislativo a uma finalidade e à aplicação do princípio da proporcionalidade como elemento da legitimidade constitucional das leis Oferece, como exemplos, precedentes colhidos na jurisprudência do STF (Gilmar Ferreira Mendes, "Controle de Constitucionalidade", Saraiva, 1990, pp. 38 a 54). 
Canotilho adverte que a lei é vinculada ao fim constitucionalmente fixado e ao princípio da razoabilidade a fundamentar "a transferência para os domínios da atividade legislativa da figura do desvio de poder dos atos administrativos" (Canotilho, "Direito Constitucional", $4^{a}$ ed., 1986, p. 739).

E, mais amplamente, o mesmo autor estuda o desvio de poder legislativo diante do princípio de que "as leis estão todas positivamente vinculadas quanto a fim pela Constituição" (Canotilho, "Constituição Dirigente e Vinculação do Legislador", Coimbra, 1982, p. 259).

\section{III - Desvio do Poder Jurisoprudencial}

A acolhida do desvio de poder como vício de ato jurisdicional não tem sido manifesta.

RESTA, aponta, na Itália, os estudos sobre o excesso de poder jurisdicional que, no entanto, tendiam a se confundir com a regra da incompetência. Na palavra de Orlando, o desvio de Poder (sviamento) seria peculiar ao ato administrativo, reservando-se ao ato jurisdicional a figura do transbordamento (straripamento) como modalidade de violação de lei) Raffaelle Resta, La Natura Giurídica del'Eccesso di Potere come Vizio Degli Atti Amministrativi, in "Studi in Onore di Federico Cammeo", vol. II, p. 338, nota 2, ep. 392).

Quando o juiz transcende à jurisdição, a doutrina italiana acolhe a noção francesa do excès de pouvoir, como modalidade de usurpação de poder, sob o rótulo de sconfiamento, ou seja de ultrapassagem dos limites da lei (Renato Alessi, ob. cit., p. 305).

O excesso de poder judiciário pressupõe, em suma a atualidade do poder do qual abusa o titular, indo além de seu real escopo.

Carnellutti destaca que "o excesso é qualidade ou atitude de poder que existe, a incompetência é expressão do poder que não existe". Daí por que "non potere e potere eccessivo sono bianco e nero".

No mais completo estudo dedicado ao tema do excesso de poder judiciário (Eccesso di Potere, in Rivista di Diritto Processuale Civile, vol. I, Parte I, 1920, pp. 33 e ss.), o excelso mestre da Universidade de Pádua identifica no abandono do fim próprio da jurisdição o elemento característico daquela espécie de vício de legalidade da conduta do juíz.

Porque o abuso de poder não é manifesto, o excesso de poder se apresenta ainda aqui a lição de Carnellutti — como "um vício oculto do ato, não um vício aparente; é como uma doença da qual o diagnóstico não se faz diretamente, mas tão-somente pelos sintomas" (ob. cit., p. 48)

Significativamente, como ilustração da assertiva, o autor traz à colação a definição de Hauriou, pertinente ao détournement de pouvoir, no qual ocorre "o ato de um agente da Administração que, permanecendo fiel à letra, sai do espírito de sua função" (ob. cit., p. 48 , nota 1 ).

Invoca a profunda distinção entre a incompetência e o excesso de poder. E como este último se caracteriza pelo "uso de poder judiciário para um fim não judiciário", 
conclui enfaticamente no sentido de que "se possa utilmente recorrer à doutrina administrativa e trazer da fecunda aplicação do conceito do sviamento estímulo e modo de aclarar a substancial unidade do fenômeno" (ob. cit., p. 54).

Os poderes do juiz, embora traçados na lei, certamente contêm uma dose de discricionariedade que lhe atribui, especialmente nas inovações da ordem pública perante as transformações sociais, um conteúdo criador do direito.

Impõe-se reconhecer, conforme a lição de Cappelletti, que "na interpretação judiciária do direito legislativo está ínsito um certo grau de criatividade". É inerente ao processo interpretativo uma certa margem de discricionariedade, que mais se exacerba quando a lei autoriza o juiz a decidir por eqüidade (Mauro Cappelletti, “Giudici Legislatori?”, Giuffré, 1984, pp. 10/14).

A liberdade facultada ao juiz na construção do direito e na ponderação dos interesses em jogo não se pode afastar, porém, do princípio da proporcionalidade, como lembra Egas Moniz de Aragão, sob o pálio da doutrina alemã (Medidas Inomimadas, in Revista Universitária de Derecho Processual, Madrid, 1990, p. 505).

A esse propósito, o ilustre mestre da Universidade do Paraná invoca expressiva decisão do Tribunal de Alçada do Estado do MS n. 91/87.

Tratava-se de litígio em que se pretendia a revisão dos encargos financeiros em contrato garantido com títulos de crédito.

Obteve o devedor medida cautelar suspensiva do protesto e da execução dos títulos de responsabilidade dos sócios e das empresas do grupo econômico até que fosse solvida a revisão contratual do valor da dívida.

A decisão concessiva da segurança invoca a lição de Larenz no sentido da necessidade de "determinar onde se situa o limite da satisfação lícita de um interesse também digno de tutela".

Entendeu-se que a suspensão ou inibição do direito do credor era, no caso, medida excessiva, podendo a tutela dos interesses dos devedores ser alcançada paralelamente mediante a revisão judicial do contrato.

Pondera o voto vencedor que "não se explica bem por que o interesse legítimo do credor há de ceder perante interesse do devedor que, nas circunstâncias do caso, não se revela de valor superior".

Daí a conclusão do acórdão, dando provimento ao apelo, sob o fundamento de que "a medida geral de inibição ou de suspensão do direito do credor se revela assim desproporcionada" (Paraná Judiciário - PJ n. 25, pp. 175 e 176).

A opção, em princípio válida por medida judicial mais severa, torna-se ilícita na medida em que excede à finalidade da competência do juiz.

É o modelo de desvio de poder jurisdicional, ainda que sem o batismo terminológico.

Egas Moniz de Aragão (ob. cit., pp. 506 e 520) lembra, a propósito da hipótese, a analogia com o preceito do art. 620 do C. Pr. Civ., segundo a qual "quando por vários meios o credor puder promover a execução, o juiz mandará que se faça pelo modo menos gravoso para o devedor".

A questão da razoabilidade nos atos jurisdicionais foi, igualmente, aflorada em decisão do STF na ação Direta de Inconstitucionalidade n. 223, conforme o voto do Relator designado para o acórdão, Min. Sepúlveda Pertence. 
Questionava-se o cabimento da Medida provisória n. 173, que vedava a concessão de medidas liminares em mandados de segurança e procedimentos cautelares.

O relator, Min. Paulo Brossard, acompanhado pelo Min. Celso de Mello, concedia a liminar suspensiva, porém a maioria da Corte acompanhou o voto denegatório do Relator designado.

Acentuando a específica natureza das medidas liminares - que não antecipam juízo de mérito, mas tão-somente visam a garantir a eficácia futura da prestação judicial - destaca o voto vencedor a tendência reinante "ao abuso das virtualidades da tutela cautelar inicial ... que traz consigo o risco do constrangimento precipitado, porque derivando essencialmente de uma cognição incompleta, a eventuais direitos da parte contrária àquela a quem, se defere a medida cautelar".

Lembra que a outorga do provimento cautelar nem sempre se mantém no caráter meramente conservativo, freqüentemente "altera a situação de fato e, não raras vezes, consiste na antecipação do provimento definitivo".

À luz da reserva indispensável, para que não se torne excessiva a medida cautelar além do requisito essencial da real existência de periculum in mora, optou pelo indeferimento da liminar.

Nesse passo, mereceu a adesão dos demais Ministros, desde o apoio do Min. Sydney Sanches, convencido da adequação, na matéria, de "certa dose de razoabilidade", com a observação do Min. Octávio Gallotti de que a concessão generosa de medidas liminares poderá conduzir a "uma inversão do risco" para inviabilidade de sentença denegatória do mandado de segurança.

Certamente, com o deferimento imoderado de medidas liminares ou cautelares, além de sua definida finalidade, estará o juiz excedendo ao escopo próprio da jurisdição, importa dizer, incidirá em vício que se identifica, substancialmente, com a natureza do desvio do poder. A competência jurisdicional estará, em tese, presente, mas seu emprego abusivo atingirá alvo diverso que não se coaduna com o conteúdo do poder exercido.

$\mathrm{Na}$ literatura nacional somente encontramos um exemplo expresso da ocorrência possível de desvio de poder no exercício da função jurisdicional.

Celso Antonio Bandeira de Mello descreve situação concreta em que, a seu juízo, poder-se-á evidenciar aquele específico vício de legalidade:

Se em Câmara de um Tribunal determinado juiz mudar seu voto, passando a acompanhar os dois outros, e o fizer deixando explícito que tal mudança é procedida com o fito de, gerando unanimidade, impedir a interposição de embargos de divergência, terá se patenteado desvio de poder, corrigível jurisdicionalmente" (O Desvio de Poder, in RDA, vol. 172, pp. 17 e 18; ver também "Discricionariedade e Controle Jurisdicional". Malheiros Editores, 1992, p. 77).

Concluindo, temos que détournement de pouvoir assim como se universalizou no direito administrativo comparado, com a exportação do modelo francês ao direito dos demais países, também merece ser estendido ao controle de atos típicos do Legislativo ou Judiciário, a título de modalidade de excesso de poder pela violação da finalidade prevista ou implícita da norma de direito. 
A matéria de fato, em tais casos, será de aferição mais difícil. A questão de direito está, porém, presente pelo princípio da necessária razoabilidade no exercício da competência constitucional ou legal, por mais discrionária que se possa entender sua latitude. A finalidade é elemento permanente de legalidade e de vinculação da conduta do agente administrativo, como do legislador ou do juiz. 


\title{
A NOVA REGULAÇÃO DOS SERVIÇOS PÚBLICOS
}

\author{
FLORIANO DE AZEVEdo MARQUES NeTO*
}

1. Introdução. II. As transformações na regulação estatal da atividade econômica. III. As transformações na noção de serviço público. IV. Contornos e desafios da nova regulação sobre serviços públicos. V Conclusão.

\section{Introdução}

1. Tratar da regulação de serviços públicos hoje significa um considerável desafio. Isso porque envolve trabalhar a relação entre duas esferas jurídicas que passam por significativas transformações nas últimas décadas.

1.1. De um lado, o conceito de regulação estatal se transmuta por força da mudança nos padrões de relacionamento entre Estado e Sociedade, pela ampliação dos campos de atuação regulatória estatal e mesmo pela introdução de fortes instrumentos de atuação estatal sobre as relações econômicas (afirmação do direito do consumidor $^{1} \mathrm{e}$ fortalecimento do direito da concorrência). A regulação, preliminarmente entendida como campo da atuação direta e indireta do Estado sobre o domínio econômico, vive uma profunda mudança de campos, instrumentos e finalidades.

1.2. Doutro bordo, a própria noção de "serviço público" vive uma profunda transformação. Tanto o processo de privatização de empresas e ativos estatais, quanto a quebra do paradigma monopolista da exploração destas atividades (e, no caso europeu, também a introdução do direito comunitário nesta seara) impactam sobremaneira não só a forma de exploração destas atividades, como os próprios instrumentos teóricos de que nós, os publicistas, lançamos mão para explicá-los nos últimos cento e tantos anos.

* Advogado. Doutor em Direito Público pela USP. Professor de Direito Administrativo da PUC-SP

1 Vale aqui uma breve digressão exemplificativa. Embora há dez anos o Código de Defesa do Consumidor estabelecesse que o usuário de serviço público devia ser caracterizado como "consumidor", a incidência do direito do consumidor sobre as relaçōes de prestação e fruição de serviços públicos era precária, pequeníssima, sendo raras as manifestações de defesa do consumidor pela não prestação, má prestação ou serôdia prestação de serviços públicos.

R. Dir. Adm.,

Rio de Janeiro, 228: 13-29,

Abr./Jun. 2002 